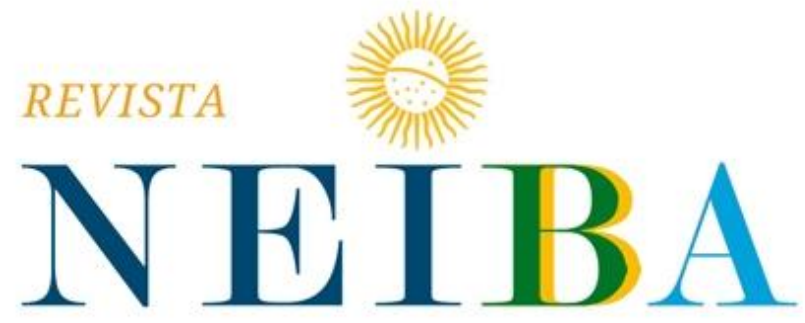

CADERNOS ARGENTINA-BRASIL

\title{
A PARCERIA RUSSO-TURCA NO SÉCULO XXI: RECONFIGURAÇÕES DE FORÇAS EM UM SISTEMA INTERNACIONAL EM CÂMBIO
}

The Russian-Turkish Partnership in the 21st Century: Reconfigurations of Forces in an International System in Change

\section{Letícia Figueiredo Ferreira ${ }^{1}$}

${ }^{1}$ Doutoranda pelo Programa de Pós-Graduação em Relações Internacionais San Tiago Dantas (Unesp/Unicamp/PUC-SP), São Paulo, São Paulo, Brasil. E-mail: leticiarierreff@gmail.com. ORCID: https://orcid.org/0000-0002-5574-6788.

Recebido em: 18 fev. 2019 | Aceito em: 27 jun. 2019

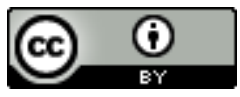

Esta obra está licenciado com uma Licença Creative Commons Atribuição 4.0 


\section{RESUMO}

A despeito de séculos de ambiguidade, marcada por períodos de convergência e de rivalidade, o relacionamento entre Rússia e Turquia, a partir de 2016, adentrou uma nova fase de aproximação estratégica. Diante da deterioração das suas relações com a Europa e os Estados Unidos, Moscou e Ancara passaram a cooperar em três áreas: segurança, energia e moeda. Esse tripé geoeconômico e geopolítico tem guiado a ação conjunta desses atores, em um processo de rearranjos de forças no sistema interestatal capitalista. O presente trabalho se destina a analisar a parceira russo-turca nesses três vértices, avaliando o alcance da mesma e suas consequências, tanto para a vizinhança desses países, quanto para o sistema internacional como um todo. Espera-se demonstrar que tal esforço russo-turco, sendo uma busca por maior autonomia, representa uma resposta às pressões exercidas pelo Ocidente.

Palavras-chave: Rússia; Turquia; inserção autônoma

\section{ABSTRACT}

Despite centuries of ambiguity, marked by periods of convergence and rivalry, the relationship between Russia and Turkey, since 2016, has entered a new phase of strategic approchement. Faced with deteriorating relations with Europe and the United States, Moscow and Ankara began to cooperate in three areas: security, energy and currency. This geoeconomic and geopolitical tripod has guided the joint action of these actors in a process of rearranging forces in the capitalist interstate system. This work aims to analyze the Russian-Turkish partnership in these three vertices, evaluating the reach of it and its consequences, both for the neighborhood of these countries and for the international system as a whole. We expect to demonstrate that such RussianTurkish effort, being a quest for greater autonomy, represents a response to the pressures exerted by the West.

Keywords: Russia; Turkey; autonomous insertion 


\section{INTRODUÇÃO}

As relações entre Rússia e Turquia têm alternado entre períodos de convergência e rivalidade, tendo os anos 2000 consagrado um novo estreitamento dos laços entre esses atores. O esforço de investigação do presente trabalho concentra-se no segundo decênio do século XXI, tendo como objetivo a análise de uma revigorada aproximação russo-turca em três áreas específicas: segurança, energia e moeda. No campo securitário, despontam a cooperação na Guerra da Síria e um acordo de fornecimento de sistemas de defesa aérea russos à Turquia. Na esfera energética, observa-se o desenvolvimento de grandes projetos de infraestrutura, como a construção do gasoduto TurkStream e da usina nuclear de Akkuyu. Já no âmbito monetário, materializa-se uma estratégia conjunta de redução do dólar em suas reservas internacionais.

Destarte, aborda-se, por meio de noticiosos, artigos científicos e documentos oficiais, o chamado Diálogo de Astana e o acordo de provisão de equipamento militar entre Moscou e Ancara. No que se refere aos investimentos em infraestrutura energética, toma-se por base as obras de Klare (2008) e Yergin (2011) para um exame do papel da Turquia, como país de trânsito, para os projetos russos. Recorre-se, ademais, aos dados da World Nuclear Association para sondar a produção de energia nuclear na Anatólia. Já nossa avaliação da mudança de política monetária desses países fundamenta-se na perspectiva cartalista de Knapp (1905) e Metri (2014).

A partir de um balanço dos desenvolvimentos recentes nessas áreas particulares, formula-se a hipótese de que a cooperação corrente entre Rússia e Turquia retrata a confluência de interesses estratégicos, em um cenário de crescente descontentamento perante os Estados Unidos e a Europa e de valorização das relações com a Ásia. Tal iniciativa de reaproximação russo-turca traz implicações para o xadrez regional, onde o acirramento das tensões entre Ocidente e Oriente delineia importantes reconfigurações de poder. Assim, espera-se evidenciar as possíveis consequências do acercamento entre Moscou e Ancara em campos estratégicos bem definidos para as suas vizinhanças, em particular, e para o Sistema Internacional, em geral. 
Além desta introdução e das considerações finais, o presente trabalho conta com quatro sessões. A primeira traz a um breve histórico das relações entre os dois países, ressaltando interesses e áreas de influência comuns, além de apontar os avanços e retrocessos que caracterizam o relacionamento russo-turco. As outras três sessões versam sobre cada um dos três vértices do tripé geoeconômico e geoestratégico que tem norteado a reaproximação recente.

\section{HISTÓRICO DAS RELAÇÕES E REAPROXIMAÇÃO RECENTE}

As relações entre Rússia e Turquia têm sido marcadas por uma forte ambiguidade. Embora, entre 1676 e 1917, os impérios russo e otomano tenham rivalizado em inúmeras guerras, os dois também viveram momentos de convergência sempre que existiam benefícios econômicos envolvidos ou alguma frustração no relacionamento com as potências europeias (ERMIDA; FERNANDES, 2013; BARRINHA, 2017). A rivalidade secular entre os dois impérios multi-étnicos euroasiáticos derivava da sua proximidade geográfica e da consequente sobreposição de áreas de influência e interesses geoestratégicos, nos Balcãs, no Cáucaso e no Oriente Médio. Ao mesmo tempo, porém, suas políticas externas norteadas por pressupostos pragmáticos lhes permitiam reconhecer as vantagens de uma eventual cooperação (BARRINHA, 2017).

No que tange aos Balcãs, território que integrava o Império Otomano, os russos se veem ligados à população balcânica por uma matriz étnico-cultural comum, baseada na cristandade ortodoxa e na origem eslava. Outrossim, a localidade possui uma importância geoestratégica para Moscou, dada sua cobiça por uma saída para águas quentes através do Mar Negro, central no comércio com o Mar Mediterrâneo e controlado pelos turcos por meio dos Estreitos de Bósforo e Dardanelos. A religião e o pan-eslavismo justificaram várias ingerências russas em assuntos internos otomanos, desaguando em duas das principais contendas russo-turcas do século XIX: a Guerra da Crimeia (1853-1856) e a Guerra Russo-Turca (1877-1878). De igual modo, a Crimeia, além de inserida na estratégia comercial e militar russa de estabilização do Mar Negro, são o berço da espiritualidade ortodoxa e da identidade russa (VASCONCELLOS, 2016). 
A competição entre Rússia e Turquia no Cáucaso do Sul e na Ásia Central, entorno estratégico direto de ambos, também se relaciona a questões étnico-culturais. Essas regiões, então ocupadas pelos impérios otomano e persa, foram conquistadas pelo Império Russo no século XIX, integrando seu território e, posteriormente, o da União Soviética (URSS) até o desmantela-mento do bloco ao fim da Guerra Fria; detendo população cuja composição étnica se entrelaça tanto aos turcos quanto aos russos. Já o Oriente Médio, entorno russo indireto e espaço de disputa com os Estados Unidos durante os anos de bipolaridade, foi governado pelo Império Otomano desde o século XVI até a Primeira Guerra Mundial, estando ligado à Turquia não apenas por laços históricos, culturais e geográficos, como também pela religião islâmica (VASCONCELLOS, 2016; SOCHACZEWSKI, 2018).

Assim, turcos e russos possuem minorias étnicas além de suas fronteiras, sendo a proteção das mesmas uma agenda comum a Moscou e Ancara. Ambos lidam, ainda, com conflitos étnicos e separatistas, como é o caso dos curdos, na Turquia, e dos jihadistas islâmicos nas fronteiras russas com os países do Cáucaso e da Ásia Central, que justificaram as ações do país nas duas guerras na Chechênia, nos anos 1990, e no combate ao Estado Islâmico, nos anos 2010. Existe, além disso, uma faceta geoeconômica na concorrência russo-turca no Cáucaso do Sul, na Ásia Central e no Oriente Médio, triângulo energético que concentram as maiores reservas mundiais de hidrocarbonetos. Tais questões, de ordem securitária e energética, serão tratadas com maior profundidade ao longo deste trabalho.

A despeito da rivalidade histórica, o relacionamento entre Rússia e Turquia, conforme supracitado, também conta com episódios de cooperação relevantes. Após o fim da Primeira Guerra Mundial e diante do declínio do Império Otomano, a URSS apoiou fortemente a Guerra de Independência da Turquia (1919-1923), vendo a expulsão das potências que ocupavam a Anatólia como um ato contra o imperialismo ocidental. Um Tratado de Amizade Turco-Soviético foi assinado em 1921, durante a luta por emancipação nacional, sendo a URSS a primeira grande potência a reconhecer o Estado turco (BARRINHA, 2017; SOCHACZEWSKI, 2018). 
Em 1925, o pacto de não-agressão foi renovado e o bom relacionamento entre os países se manteve até a Segunda Guerra Mundial, mesmo frente às chamadas Revoluções de Atatürk, uma série de reformas internas para tornar a Turquia uma nação moderna, laica e ocidentalizada.Contudo, a militarização dos estreitos turcos, em 1936, e a adoção de uma "neutralidade ativa" durante quase toda a guerra levaram a uma nova deterioração das relações russo-turcas. Após o fim do conflito, os russos condicionam a renovação do tratado de amizade ao estabelecimento de bases em Bósforo e Dardanelos - de modo a assegurar a passagem do Mar Negro para o Mediterrâneo - e à cessão das províncias de Kars e Ardahan, próximas aos territórios dos atuais Estados da Geórgia e da Armênia, então repúblicas soviéticas. A Rússia deixou, portanto, de ser uma aliada e voltou a ser vista como ameaça potencial (SOCHACZEWSKI, 2018).

No âmbito da Guerra Fria, buscando se reposicionar no sistema internacional, a Turquia encontrou nos Estados Unidos seu aliado primordial. Com o lançamento da Doutrina Truman, em 1947, Ancara passou a receber recursos do Plano Marshall e adotou de vez uma postura pró-Ocidente. Em 1952, aderiu à Organização do Tratado do Atlântico Norte (OTAN) e se tornou a ponta-de-lança da aliança euro-atlântica no espaço soviético. A década de 1960 testemunhou um período de relativo degelo nas relações entre Rússia e Turquia, mediante a maior abertura do governo Krushchev e a insatisfação de Ancara com a falta de apoio de Washington na lide com a Grécia pelo Chipre. Entretanto, a virada no relacionamento dos dois países só ocorreria, de fato, nos anos 1980, com a abertura política encetada pelo primeiro ministro turco, TurgutÖzal, e a assinatura de acordos comerciais no setor de gás natural (BARRINHA, 2017).

Embora a Rússia ainda visse a Turquia como uma representante dos interesses estadunidenses em seu entorno regional, o fim da bipolaridade desembaraçou os vínculos entre os dois países. Assim, em 1992, Moscou e Ancara anunciaram seu reconhecimento diplomático mútuo, e assinaram o Tratado sobre os Princípios da Relação entre a República da Turquia e a Federação Russa. No início dos anos 2000, a ascensão de Vladimir Putin, na Rússia, e do Partido da Justiça e Desenvolvimento (AKP), na figura de Recep Tayyip Erdoğan, na Turquia, estreitaria ainda mais os laços entre os 
dois países. Visando expandir suas relações nas áreas de comércio, energia, turismo e defesa, ambos celebraram, em 2001, o Plano de Ação sobre Cooperação na Eurásia e, em 2004, a Declaração Conjunta sobre a Intensificação da Amizade e Parceria Multidimensional, revisada em 2009. Já em 2010, foi criado o Conselho de Cooperação Russo-Turca de Alto Nível, que se reúne anualmente e visa o aprimoramento das relações econômico-comerciais, culturais e técnico-científicas entre os países (Idem, 2017).

O mais recente tensionamento nas relações russo-turcas se deu no final de 2015, quando uma crise diplomática se instaurou após o abatimento de um caça russo pelas forças armadas da Turquia na sua fronteira com a Síria. Essa não foi suficiente, porém, para derruir, em termos definitivos, a colaboração russo-turca e, em junho de 2016, veio o pedido de desculpa por parte da Turquia. Na esteira da reaproximação russoturca se deu a tentativa de golpe militar contra Erdoğan, em julho daquele ano, e o assassinato do embaixador russo na Turquia, Andrei Karlov, por um policial turco, em dezembro. O primeiro, de acordo com Ancara organizado pelo movimento Hizmet com a anuência dos Estados Unidos, foi frustrado graças a um aviso da inteligência russa às autoridades turcas sobre as movimentações golpistas. O segundo, ocorrido após protestos na Turquia contra o envolvimento russo na Guerra na Síria, não malo-grou a normalização das relações russo-turcas (PAUTASSO, 2017).

Isso porque os dois países já vinham, paulatinamente, superando a condição de aliados situacionais para consolidar uma parceria estratégica de longo prazo, através de projetos de cooperação em âmbitos sensíveis da segurança nacional; como nos setores de armas de alta tecnologia, energia nuclear e fornecimento e trânsito de gás natural (ISHCHENKO, 2017). Hodiernamente, as relações entre Rússia e Turquia encontram-se em um estágio de elevada sinergia, caracterizada pela cooperação em três áreas estratégicas preferenciais: segurança, energia e moeda. Como se abordará a seguir, as três formam um tripé geoeconômico e geopolítico que tem guiado a ação conjunta de Moscou e Ancara, em meio ar e arranjos de força no sistema internacional e à reformulação das suas estratégias de acumulação de poder e riqueza. 


\section{O VÉRTICE SECURITÁRIO: ASTANA E O ACORDO ARMAMENTÍCIO}

Os primeiros esforços de mediação da guerra civil síria, deflagrada, no início de 2011, por uma série de manifestações contra o governo de Bashar al-Assad no contexto da Primavera Árabe, emanaram da Liga Árabe; mas logo a gestão do processo de paz foi assumida pela Organização das Nações Unidas (ONU). A estratégia geral da organização, frente aos sucessivos fracassos em estabelecer negociações diretas entre o governo e a oposição sírios, foi empregar a influência de potências regionais e internacionais na Síria para alcançar um cessar-fogo. O Processo de Genebra, como ficaram conhecidas as reuniões subsidiadas pelas Nações Unidas, teve como ponto fulcral uma pacificação pautada no compartilhamento de poder entre as partes do conflito e no estabelecimento de um governo de transição (LUNDGREEN, 2016).

Apesar dos esforços conduzidos pela ONU, o Processo de Genebra não obteve desfecho positivo devido à agenda conflitante entre as potências externas envolvidas no conflito, à relutância de al-Assad e das forças antirregime em concordar com uma solução mutuamente aceitável e à não inclusão de importantes atores regionais, como o Irã. As negociações no âmbito das Nações Unidas foram paralisadas em 2016, só sendo retomadas a partir de uma iniciativa de mediação alternativa, entabulada pela Rússia. Após a vitória do regime sírio sobre a oposição em Daraya e Aleppo, Rússia, Turquia e Irã passaram a realizar, a partir de janeiro de 2017, uma série de conversações em Astana, capital do Cazaquistão, para consolidar o cessar-fogo, combater os grupos salafi-jihadistas no país e iniciar um diálogo de paz (PRIYA, 2017).

O Processo de Astana, como ficou conhecida a iniciativa, surgiu da maior aproximação regional entre Rússia e Turquia, com Moscou tirando proveito do menor engajamento da administração Obama na Síria em seus últimos meses de mandato e da mudança de posição de Ancara, que, até então, apoiava os rebeldes sírios e a deposição de al-Assad. Para além da supracitada tentativa fracassada de golpe no país, a redefinição pela Turquia dos seus interesses na Síria e das suas relações com forças regionais e internacionais resultou do apoio dos Estados Unidos às forças curdas no norte da Síria, particularmente às Unidades de Proteção Popular (YPG). Essas integram o braço militar do Partido Democrático Curdo (PYD), ramo sírio do Partido dos 
Trabalhadores do Curdistão (PKK), que Ancara classifica como grupo terrorista e uma ameaça à sua segurança nacional (AL JAZEERA CENTRE FOR STUDIES, 2017).

A reconciliação russo-turca permitiu a emergência de um processo de pacificação relativa-mente menos ambicioso do que o de Genebra, visando o fim das hostilidades ao invés da transição política imediata. Centradas em questões humanitárias e na obtenção de um cessar-fogo estável, essas reuniões simbolizam uma mudança geopolítica, visto que, ao contrário das discussões em Genebra, não são encabeçadas pelas potências ocidentais (PRIYA, 2017). A coordenação entre Rússia, Turquia e Irã foi bem-sucedida em reunir, na mesma mesa de negociações, representantes do regime e da oposição. A ênfase no combate ao Daesh e outros grupos salafi-jihadistas garantiu a participação dos grupos de oposição sírios, que não queriam ser vistos como alinhados aos extremistas. A participação do governo sírio, por sua vez, foi assegurada pela exclusão da deposição imediata de al-Assad como condição de negociação, mudando as regras de Genebra ${ }^{1}$ (AL JAZEERA CENTRE FOR STUDIES, 2017).

O Diálogo de Astana produziu um grupo de monitoramento trilateral e um mecanismo de troca de prisioneiros, entrega de corpos e identificação de desaparecidos. Seu maior progresso foi, porém, o estabelecimento de quatro zonas de desescalada na Síria ${ }^{2}$, de acordo com o mapa acordado por um grupo de trabalho conjunto. A implementação dessas áreas seguras tinha como propósito o encerramento das hostilidades entre rebeldes e forças pró-Assad, incluindo ataques aéreos; a desobstrução do acesso rápido à ajuda humanitária;a restauração da infraestrutura básica, como redes de distribuição de água e de eletricidade;e o retorno seguro e voluntário de refugiados e deslocados internos (AL JAZEERA, 2017; PRIYA, 2017; RÚSSIA, 2017).

Foi também no âmbito do Processo de Astana que se realizou, em Sochi, em janeiro de 2018, o Congresso Nacional de Diálogo da Síria, visando expandir o leque de

\footnotetext{
${ }^{1}$ Moscou apresentou um esboço da nova constituição síria que propunha transferir parte dos poderes do presidente ao parlamento, para então realizar eleições presidenciais, que permitiriam ao povo sírio decidir o destino de al-Assad (AL JAZEERA CENTER FOR STUDIES, 2017).

${ }^{2}$ A primeira abrange a província de Idlib, bem como o nordeste de Latakia, o oeste de Aleppo e o norte de Hama. A segunda engloba o enclave de Rastan e Talbiseh, na província de Homs; enquanto a terceira compreende Ghouta Oriental, na zona rural de Damasco. A quarta zona, por fim, é constituída pelas áreas do sul do país, ao longo da fronteira com a Jordânia (AL JAZEERA, 2017; TALUKDAR; ANAS, 2018).
} 
participação da sociedade civil síria - envolvendo grupos tribais, religiosos e étnicos, incluindo os curdos - na formulação de uma nova constituição. Por outro lado, como mencionado anteriormente, as negociações de Astana ajudaram a reviver as conversações de Genebra, obtendo apoio de Washington e da ONU e evitando confronto ou duplicação do processo de pacificação (PRIYA, 2017). Na prática, porém, o Processo de Genebra foi rapidamente ofuscado pelo êxito do Processo de Astana, que teve como resultados tangíveis a redução da violência e o funcionamento das zonas de desescalada, as quais refrearam o fluxo de refugiados e deslocados internos.

Apesar das divergências entre Rússia e Turquia sobre o caminho político a se seguir na Síria - com a primeira apoiando um sistema federal e não descartando a possibilidade de uma região curda autônoma, algo inaceitável para a última (TRT WORLD, 2018) -, o casamento de conveniência serve aos interesses de ambas. Frente à negligência dos Estados Unidos, da União Europeia e da OTAN, a decisão da Turquia de trabalhar mais de perto com a Rússia foi uma resposta a uma ameaça nacional que emana da Síria e do Iraque: os curdos (DURAN, B. 2018). Embora Moscou considere o YPG um ator legítimo nas negociações de paz, ao contrário de Washington, não arma o grupo e permitiu o avanço das forças militares turcas na operação que, em março de 2018, conquistou o bastião curdo de Afrin (TRT WORLD, 2018).

A Rússia, por sua vez, tenta consolidar os ganhos estratégicos com o regime alAssad, mantendo sua posição no Mediterrâneo e expandindo suas instalações militares no Oriente Médio $^{3}$, onde recuperou grande parte da influência política perdida para os Estados Unidos no final da década de 1970. Nesse sentido, incitou a participação da Turquia no processo diplomático para limitar o raio de ação do Irã e de al-Assad - o qual Moscou já deu sinais de que não deseja sustentar indefinidamente -, garantindo que o Kremlin tenha a palavra final em qualquer solução política para o conflito (FRIEDMAN, 2017). Além de fortalecer sua posição regional, a influência na Síria confere à Rússia maior poder de barganha internacional, servindo de instrumento de mitigação das restrições postas pelas sanções econômicas e diplomáticas ocidentais.

\footnotetext{
3 Em dezembro de 2017, a Rússia e a Síria anunciaram o prolongamento do contrato de arrendamento das bases militares de Tartus e da Base Área de Khmeimim até 2092 (TALUKDAR; ANAS, 2018).
} 
Na esteira da promessa dos Estados Unidos de saírem da Síria em breve, não resta dúvida de que os países ocidentais temem que seus interesses na região sejam marginalizados (DURAN, B. 2018). Nesse sentido, a cooperação russo-turca em Astana não só mudou os rumos da Guerra da Síria, como têm definido as relações de poder no Oriente Médio. A colaboração no campo da segurança não se restringe, todavia, à coordenação na Guerra da Síria, tendo um acordo de compra de mísseis antiaéreos S400 da Rússia pela Turquia sido assinado no final de 2017. Alvo de críticas vigorosas dos Estados Unidos e de outros membros da OTAN, sob o argumento de incompatibilidade dos S-400 com o escudo de defesa da aliança (SCIMIA, 2018), o acordo tem alimentado a corrosão do relacionamento de Ancara com o Ocidente.

\section{O VÉRTICE ENERGÉTICO: O TURKSTREAM E A USINA DE AKKUYU}

A cooperação que atualmente se desenrola entre Rússia e Turquia no campo da energia não é inédita. No século XIX, o carvão russo abasteceu a frota naval do Império Otomano frente à insuficiência das reservas turcas para alimentar a rápida expansão do seu poder marítimo. O mesmo ocorreu com o petróleo, no século XX, quando a Rússia, substituindo os Estados Unidos e a Alemanha, tornou-se o principal fornecedor de Ancara (ERMIDA; FERNANDES, 2013). Desde a década de 1990 até os dias atuais, contudo, a dependência energética turca em relação à Moscou está majoritariamente atrelada às importações de gás natural (BARRINHA, 2017).

Segundo dados da Internacional Energy Agency (IEA), dentro do contexto internacional de "globalização da demanda por energia" (YERGIN, 2011), as importações líquidas de gás natural da Turquia cresceram quase 80\% desde 2005. Tal aumento foi impulsionado pelo maior consumo de gás no setor residencial, após a gaseificação em grande escala; pelo aumento dos investimentos privados em usinas a gás; e pelo consumo crescente no setor industrial. Em 2015, das importações totais de gás natural da Turquia, 55,1\% foram provenientes da Rússia, sendo os gasodutos dominantes na estrutura de importação, já que o Gás Natural Liquefeito (GNL) ainda desempenha um papel pequeno no país, com apenas dois terminais de recepção em operação. A Turquia exporta um volume ínfimo de gás natural para a Grécia, tendo 
maior importância para o consumo energético europeu como país de trânsito (IEA, 2016).

Ancara possui uma antiga ambição de se tornar um hub energético na Eurásia, dada sua posição geográfica relativa, como uma ponte natural entre os principais produtores de gás nas regiões do Cáspio, no Cáucaso do Sul, do Oriente Médio e da Rússia e os principais consumidores da Europa. Esse objetivo visa assegurar tanto o seu abastecimento e segurança energética, quanto a manutenção de boas relações com a União Europeia (UE), bloco regional que tenta integrar há mais de quarenta anos. A Europa, sobretudo Central e Oriental, tal como a Turquia, é extremamente dependente do gás natural da Rússia, que tem utilizado a questão energética como arma política em seu relacionamento com os vizinhos (ERMIDA; FERNANDES, 2013).

As crises de abastecimento provocadas por disputas sobre os preços do gás entre a Rússia e a Ucrânia, em 2006 e em 2009, pelo conflito militar com a Geórgia, em 2008, e pela ocupação do Leste da Ucrânia e anexação da Crimeia, em 2014, aceleraram as medidas da UE para minimizar a dependência da Rússia e do trânsito de gás via Ucrânia, Moldávia e Bielorrússia. O objetivo de diversificação de rotas se materializou na construção do gasoduto russo-alemão NordStream, em operação desde 2011, e, mais recentemente, nas negociações do NordStream II, que, criticado pelos Estados Unidos e pelos países do Leste Europeu, pretende duplicar a capacidade de distribuição do gás russo via Mar Báltico (LOSKOT-STRACHOTA, 2016).

Já a diversificação de fornecedores, entre os existentes no Cáucaso do Sul, na Ásia Central e no Oriente Médio, tem sido buscada por meio da construção do Southern Gas Corridor(SGC). Formado pelo South Caucasus Pipeline (SCP)4, inaugurado em 2007 e em expansão desde junho de 2018, e pelos Trans-Anatolian Pipeline (TANAP) e TransAdriatic Pipeline (TAP) ${ }^{5}$, ainda em construção, o SGC é um projeto concorrente ao NordStream // que transportará gás natural do campo de ShahDeniz, no Azerbaijão, até o sul da Europa, passando pelos territórios da Geórgia, Turquia, Grécia, Albânia e Itália(Idem, 2016; SIDDI, 2017).A relevância de Ancara para a política de segurança

\footnotetext{
${ }^{4}$ Construído com o apoio dos Estados Unidos, transporta gás do Azerbaijão à Turquia, passando pela Geórgia.

5 Substituiu o projeto do Nabucco Pipeline, cancelado em 2013, que passava pela zona econômica exclusiva (ZEE) da Turquia no Mar Negro.
} 
energética da UE se explica não apenas pela sua função como país de trânsito para o SGC, mas também pela sua proximidade geográfica e seu relacionamento histórico com grandes produtores de petróleo e gás natural.

No que tange ao Cáucaso e à Ásia Central, além de ter uma ligação cultural, linguística e religiosa com essas regiões, Ancara - incentivada por Washington, no âmbito da OTAN - as apoiou política e economicamente após o fim da Guerra Fria e o desmembramento da URSS. Contudo, embora a Turquia tenha aumentado sua esfera de influência, ambas permanecem estreitamente ligadas à Rússia. Já no Oriente Médio, os turcos fortaleceram seus laços econômicos e político-diplomáticos com os países árabes, mantendo, em especial, um bom relacionamento com o Irã, detentor das maiores reservas de gás da região (ERMIDA; FERNANDES, 2013).

Se, por um lado, a Turquia e a Europa anseiam reduzir sua vulnerabilidade energética decorrente da dependência do gás russo, a Rússia, por outro, busca manter as importações para esses dois grandes mercados consumidores. No caso da Turquia, como se vem argumentando, o interesse não é apenas de ordem econômica - ainda que Ancara seja o segundo maior mercado da estatal russa Gazprom depois da Alemanha -, mas também geopolítica. Assim, Moscou, que já fornecia gás natural à Turquia por meio da Blue Stream, através do Mar Negro, e do corredor Trans-Balcânico, através da Ucrânia e dos Balcãs orientais, propôs a construção do TurkStream no final de 2014 (BARRINHA, 2017; SHAHBAZOV, 2018). Esse substituiu o projeto do South Stream, que previa o transporte de gás da Rússia para a Áustria através do Mar Negro ${ }^{6}$, mas foi cancelado após a crise da Ucrânia e o endurecimento da legislação energética da UE.

Em 2016, no contexto da reaproximação russo-turca, Ancara e Moscou retomaram as negociações e assinaram um acordo intergovernamental para a construção do TurkStream pela Gazprom e a estatal turca BOTAS. As obras tiveram início em 2017 e incluem duas linhas que ligam a Rússia à Turquia também pelo Mar Negro. A primeira permitirá o redirecionamento das exportações de gás do corredor Trans-Balcânico, findando a dependência do trânsito pela Ucrânia e por outros países. Já a construção da

\footnotetext{
${ }^{6}$ O South Stream passaria pela ZEE turca e pelos territórios da Bulgária, da Grécia e da Itália.
} 
segunda linha, destinada às exportações para o sul da Europa, dependerá de um mercado mais amplo e de desdobramentos políticos envolvendo a construção do NordStream I/ e os avanços do SGC. Paralela à primeira, porém estendendo-se à fronteira greco-turca, essa segunda linha poderia - através de um gasoduto complementar, o Poseidon Pipeline - fornecer gás à Itália, terceiro maior cliente nacional da Gazprom e ainda dependente dos gasodutos de trânsito ucraniano (SIDDI, 2017; GAZPROM, 2018).

Além do petróleo e do gás natural, Turquia e Rússia têm interesses comuns no campo da energia nuclear. Também em 2016 foram resgatadas as negociações a respeito da construção da primeira planta nuclear turca, em Akkuyu, na província costeira mediterrânea de Mersin. O projeto, que era debatido desde a década de 1970, só foi acordado pelos chefes de Estado russo e turco em 2010, quando assinou-se um acordo intergovernamental para a estatal russa Rosatom construir, possuir e operar quatro reatores 1200 MWe AES-2006 na usina de Akkuyu. O empreendimento de US\$ 20 bilhões visa atender a 10\% das necessidades energéticas de Ancara até 2025, quando todos os reatores entrarem em operação. Espera-se que o primeiro reator já esteja operacional em 2023, para marcar o centenário da República da Turquia (DURAN, A. 2018; WORLD NUCLEAR ASSOTIATION, 2018).

Em abril de 2018, o início das obras foi celebrado pelos presidentes Putin e Erdoğan em uma cerimônia simbólica. A partir desse projeto, a Turquia deseja reduzir seu consumo de gás natural para produção de eletricidade para menos de $30 \%$; enquanto à Rússia, de sua parte, interessa controlar investimentos no setor de energia e expandir a sua própria rede para o sul (DURAN, A. 2018). Além da usina de Akkuyu, uma segunda planta nuclear, em Sinop, foi leiloada à um consórcio franco-japonês em 2013, estando em curso um estudo de viabilidade, ainda sem previsão de conclusão. Já a China demonstrou a intenção de construir uma terceira planta, com tecnologia derivada dos Estados Unidos, em local ainda a ser definido (WORLD NUCLEAR ASSOTIATION, 2018).

Klare (2008) vaticinou o surgimento de uma nova ordem internacional de energia, de poderes crescentes e recursos minguantes, destinada a produzir rivalidades entre um grupo cada vez maior de Estados consumidores de energia para controlar as 
reservas remanescentes de hidrocarbonetos do planeta. Para melhorar suas posições vis-à-vis uns aos outros, os países com deficiência energética poderiam forjar parcerias estratégicas com sócios ricos em energia, frequentemente cimentando tais arranjos com transferências de armas e novas ou renovadas alianças militares. Além de exacerbar conflitos, a intensificação da competição por energia também transforma a forma como os policy makers olham para o mundo, com regiões com reservas inexploradas de energia adquirindo importância global repentina (KLARE, 2008).

Simultaneamente, como aponta Yergin (2011), apesar de grandes inovações nos últimos anos e de investimentos progressivos em energias alternativas, a energia fóssil segue sendo a matriz energética mundial. Portanto, o autor afirma, a disputa pelo acesso ao e controle de petróleo e gás natural, gasoso ou liquefeito, continua a ser um fator decisivo no jogo de poder político, econômico e militar entre os Estados nacionais. A demanda crescente por energia e o risco de escassez de recursos cria uma pressão elevada sobre os líderes nacionais para satisfazer as necessidades energéticas de seus países. Por conseguinte, torna-se imperativo uma antecipação de riscos e respostas rápidas (YERGIN, 2011).

Isto posto, os mercados consumidores de gás na Europa e na Turquia são consideravelmente grandes e suas importações tendem a continuar crescendo no futuro, não sendo o fornecimento do Azerbaijão sozinho, através do SGC, capaz de substituir o fornecimento da Gazprom. Não obstante, a possibilidade de outros grandes produtores de gás se unirem ao projeto, como o Irã ou Turcomenistão, entra no cálculo estratégico da Rússia, que tem mobilizado forças para, através da Nord Stream // e da Turk Stream salvaguardar os mercados no norte e no sul da Europa, bem como na Turquia. Já a cooperação nuclear entre Ancara e Moscou, iniciativa pioneira russa já acompanhada por projetos de outras grandes potências, responde ao anseio russo de controle de empreendimentos energéticas no seu perímetro de segurança, bem como ao interesse turco de diversificar suas fontes de energia.

\section{O VÉRTICE MONETÁRIO: A “DESDOLARIZAÇÃO”}


Entre o final de 2017 e o início de 2018, a Rússia e a Turquia reduziram significativamente a sua participação na dívida externa dos Estados Unidos, trocando os títulos do Tesouro norte-americano por uma maior quota de ouro nas suas reservas internacionais. A opção russa e turca não representa uma grande perda para Washington, uma vez que países como a China, o Japão e até mesmo o Brasil detêm um número muito maior de títulos da dívida pública estadunidense, avaliada em quase US\$ 21,2 trilhões. Entretanto, a decisão de Moscou e de Ancara demonstra uma tendência em curso em outros países do Oriente, como na Bielorrússia, na Índia e no Cazaquistão: a fuga do dólar para o ouro (BERSHIDSKY, 2018).

A Rússia tem tentado diminuir sua dependência das divisas estadunidenses frente às sanções econômicas adotadas por Washington e seus aliados ocidentais, tendo Moscou declarado que não pode confiar no sistema financeiro encabeçado pelo dólar porque os Estados Unidos têm violado as regras da Organização Mundial do Comércio de forma sistemática. Além da troca do dólar por ouro e outras moedas na composição das suas reservas, a Rússia elevou as transações em divisas nacionais com seus parceiros comerciais, reduzindo a demanda por dólares nesses países. Destarte, as trocas em rublos na União Econômica Euroasiática aumentaram; a Rússia assinou acordos com a Turquia, o Irã e o Azerbaijão para evitar o uso do dólar em transações internacionais; a China abriu a primeira divisão do seu Banco de Indústria e Comércio, em Moscou, para promover trocas em renminbis; e a10a cúpula dos BRICS discutiu a realização de operações em moedas nacionais em vez do dólar (SELIVERSTOVA, 2018).

A Turquia, por sua vez, decidiu se desfazer dos títulos da dívida pública norteamericana diante das críticas às reformas políticas levadas a cabo no país por Erdoğan. Em agosto de 2018, o anúncio do congelamento de bens dos ministros do Interior e da Justiça turcos e o aumento das taxas sobre o aço e o alumínio turcos - em retaliação à prisão de um pastor estadunidense pelo governo turco sob alegação de terrorismo e espionagem - levaram à uma desvalorização histórica da lira. A crise foi mais uma na lista de eventos que compõe um longo processo de deterioração das relações da Turquia com os Estados Unidos desde a tentativa de golpe militar no país, em 2016. As

7 Criada em 2015, é formada pela Armênia, pela Bielorrússia, pelo Cazaquistão, pelo Quirguistão e pela Rússia. 
tensões só foram aliviadas no início de novembro, quando levantaram-se as sanções impostas pelas duas partes (MIDDLE EAST EYE, 2018).

As razões da adoção de tal política monetária pela Rússia e pela Turquia tornam-se mais claras à luz da teoria cartal da moeda, de Knapp (1905). Ao contrário das interpretações tradicionais, que tratam a moeda como um bem público, isto é, uma construção coletiva e espontânea que emerge como um veículo facilitador de trocas; a teoria cartalista incorpora a dimensão do poder às questões monetárias. Desse modo, o economista alemão assevera que a moeda de conta é uma denominação arbitrária e abstrata que depende do poder político que a proclama. Essa prerrogativa decorre da capacidade da autoridade central, detentora de instrumentos de violência, de tributar a população do território que essa domina, o espaço de reconhecimento social - e, portanto, de validade - da moeda (KNAPP, 1905).

Essa lógica se aplica ao sistema interestatal e à moeda de denominação internacional. Conforme argumenta Metri (2014), a escolha da moeda internacional é também um processo político, sendo o resultado de movimentos bem-sucedidos de expansão do espaço de circulação e validação da moeda de um Estado específico. Isso é alcançado por meio do exercício da força, através, por exemplo, de conquistas territoriais, da dominação de zonas estratégicas ou de ações diplomáticas de negociação coercitiva. Ao mesmo tempo, a internacionalização de uma moeda nacional acentua a competição dentro do sistema interestatal capitalista, considerando que um país operar na moeda de outrem reforça as relações hierárquicas e assimétricas que beneficiam o emissor da moeda internacional (METRI, 2014).

Assim, o dólar, como a libra no passado, é hoje a moeda internacional não por livre escolha dos diferentes Estados nacionais que compõe o sistema, mas sim por imposição da potência militar hegemônica. Ainda que o abandono total do dólar não seja possível, dado o veto que tal isolamento ainda implica à expansão econômica e políticade qualquer país, o processo de "desdolarização" de Moscou e Ancara, entre outros Estados asiáticos,visa um aumento da sua independência monetária perante o sistema financeiro internacional, sobretudo mediante o atual período de turbulência econômica. 


\section{CONSIDERAÇÕES FINAIS}

O recente acercamento entre Rússia e Turquia faz parte de uma estratégia de reafirmação de posições no sistema interestatal capitalista e de contenção da influência ocidental na sua vizinhança. Pautada em três campos principais, nomeadamente segurança, energia e moeda, essa emergiu do crescente descontentamento de Moscou e Ancara com os Estados Unidos e a Europa, e do fortalecimento de projetos eurasianistas em ambos. Frente ao deslocamento do centro de acumulação capitalista mundial para a Ásia e ao rearranjo de forças em curso no continente, Rússia e Turquia, historicamente divididas entre suas frentes europeias e asiáticas, têm priorizado o relacionamento com o Oriente na consecução das suas agendas de política externa e, em última instância, nas suas estratégias de acumulação de poder e riqueza.

No Oriente Médio, o Diálogo de Astana permitiu uma reorganização da ordem regional, ao catapultar a Rússia e a Turquia, juntamente com o Irã, para a liderança das operações de pacificação da Síria. Isso permitiu um avanço tanto de Moscou sobre uma antiga região de disputa com Washington, a fim de assegurar seu perímetro de segurança e sua saída para as águas quentes do Mediterrâneo; quanto de Ancara sobre área que no passado compunha o Império Otomano e com a qual os turcos conservam laços étnicos, culturais, linguísticos e religiosos, visando combater as milícias curdas na fronteira com a Síria, questão que, antes já delicada, sofreu um processo de securitização durante os governos do AKP.

A Ásia Central e o Cáucaso do Sul, particularmente o entorno do Mar Cáspio, localidades no passado dominadas pelos poderes russo e turco, também têm sido alvo da projeção de poder político e econômico de Moscou e de Ancara. Com o Oriente Médio, formam um triângulo energético que concentra as maiores reservas de hidrocarbonetos do globo, pelas quais as grandes potências ocidentais - além de outras potências asiáticas, como a China - competem. Enquanto a Turquia busca explorar sua posição geográfica estratégica, como via de comunicação entre produtores e consumidores de petróleo e gás natural, a Rússia tenta controlar os desenvolvimentos energéticos na região para assegurar sua posição como fornecedora de gás natural, 
pilar da sua economia e relevante elemento de barganha no relacionamento com a Europa.

Por fim, a coordenação de política monetária, em uma tentativa de "desdolarização" das suas economias, assim como a cooperação em segurança e energia, responde às pressões do Ocidente - diplomáticas e econômicas - sobre regimes que vem assumindo condutas nacionalistas e mesmo autoritárias. Ambos têm adotado políticas externas independentes, de modo a se desvincular de um relacionamento com os vizinhos europeus cada vez mais visto como infrutífero. Entre os turcos, há uma frustração de longa data com as tentativas malogradas de adentrar a comunidade europeia. Já no caso russo, o avanço das instituições euro-atlânticas, nomeadamente a União Europeia e a OTAN, até os limites das suas fronteiras, ao ameaçar a integridade física daquele país, levou a novas demonstrações do poder militar de Moscou no Leste Europeu. A consequência da procura desses países por uma inserção mais autônoma em um sistema hierárquico de Estados tem sido, em suma, o aumento da frequência dos choques com o Ocidente, sobretudo no tabuleiro asiático, de crescente importância estratégica. 


\section{REFERÊNCIAS BIBLIOGRÁFICAS}

AL JAZEERA CENTRE FOR STUDIES. Between Astana and Geneva: The Outlook of Conflicting Agendas in the Syrian Crisis, 2017. Disponível em: <http://studies.aljazeera.net/mritems/Documents/2017/3/1/6fba8f853ff74a6fb9e9551 5b6186367_100.pdf>. Último acesso em: 2/11/2018.

BARRINHA, André. Relações Rússia-Turquia: da rivalidade à parceria estratégica.In:DAEHNHARDT, Patrícia; FREIRE, Maria Raquel (Org.).A Política Externa Russa no Espaço Euro-Atlântico: Dinâmicas de cooperação e competição num espaço alargado. Coimbra: Imprensa da Universidade de Coimbra, 2014.

BERSHIDSKY, Leonid. WhyRussiaandTurkey Are Such Gold Bugs. Bloomberg, 2018. Disponível em: <https://www.bloomberg.com/opinion/articles/2018-06-27/why-russiaand-turkey-are-such-gold-bugs>. Últimoacessoem: 2/11/2018.

DURAN, Aram. Akkuyu nuclear plant: Turkey and Russia's atomic connection. Deutsche Welle, 2018. Disponível em: <https://www.dw.com/en/akkuyu-nuclear-plant-turkeyand-russias-atomic-connection/a-43241154>. Últimoacessoem: 2/11/2018.

DURAN, Burhanettin. West responsible for Turkey's partnership with Russia, Iran in Syria. Daily Sabah, 2018. Disponível em: <https://www.dailysabah.com/columns/duranburhanettin/2018/04/09/west-responsible-for-turkeys-partnership-with-russia-iran-insyria>. Último acesso em: 2/11/2018.

ERMIDA, Graça; FERNANDES, José Pedro Teixeira. A Relevância Geoestratégica da Turquia para a Segurança Energética da União Europeia: o Caso do Gás Natural. Nação e Defesa, № 136, 5a Série, 2013, p. 253-276.

FRIEDMAN, Brandon. Russia, Turkey, and Iran: Cooperation and Competition in Syria. Tel Aviv Notes,v. 11, n. 2, 2017, p. 1-8. Israel: Tel Aviv University, The Moshe Dayan Center for Middle Eastern and African Studies.

GRAZPROM. TurkStream: Gas exports to Turkey and southern and southeastern Europe, 2018. Disponível em: <http://www.gazprom.com/projects/turk-stream/>. Último acesso em: 2/11/2018.

INTERNATIONAL ENERGY AGENCY (IEA). Energy Policies of IEA Countries: Tur-key 2016 Review, 2016. Disponível em:

<https://www.iea.org/publications/freepublications/publication/EnergyPoliciesoflEACo untriesTurkey.pdf>. Último acesso em: 2/11/2018.

ISHCHENKO, Rostislav. Um avanço no sul: como a Rússia se consolidou na Turquia. PhA НОВОСТИ, 2017. Disponível em:

<https://ria.ru/analytics/20170819/1500651089.html>. Último acesso em: 2/11/2018. 
KLARE, Michael T. Rising Powers, Shrinking Planet: How Scarce Energy is Creating a New World Order. Oxford: Oneworld Publications, 2008.

KNAPP, Georg Friedrich (1905). The State Theory of Money. San Diego: Simon Publications, 2003.

Leaders of Astana trio meet in Ankara for Syria talks. TRT World, 2018. Disponível em: $<$ https://www.trtworld.com/mea/leaders-of-astana-trio-meet-in-ankara-for-syria-talks16408>. Últimoacessoem: 2/11/2018.

LOSKOT-STRACHOTA, Agata. Nord Stream 2: policy dilemmas and the future of EU gas market. Policy Brief, v. 2, 2016. Oslo: Norwegian Institute of International Affairs.

LUNDGREN, Magnus. Mediation in Syria: Initiatives, Strategies, and Obstacles, 20112016. Contemporary Security Policy, v. 37, n. 2, 2016, p. 273-288.

METRI, Maurício. Poder, Riqueza e Moeda na Europa Medieval: A Preeminência Naval, Mercantil e Monetária da Sereníssima República de Veneza nos séculos XIII e XV. Rio de Janeiro: Editora FGV, 2014.

PAUTASSO, Diego. A Rússia, as relações com a Turquia e os efeitos sobre o conflito na Síria. Revista Mundorama, 2017. Disponível em:

$<$ https://www.mundorama.net/?article=a-russia-as-relacoes-com-a-turquia-e-osefeitos-sobre-o-conflito-na-siria-por-diego-pautasso>. Últimoacessoem: 2/11/2018.

PRIYA, Lakshmi. Astana Talks: A Prelude to Peace in Syria. Institute for Defense Studies and Analyses, 2017. Disponível em: <https://idsa.in/backgrounder/astana-talks-aprelude-to-peace-in-syria_Ipriya_271117>. Último acesso em: 2/11/2018.

RÚSSIA. Ministério das Relações Exteriores. Memorandumon the creation of deescalationareas in the SyrianArabRepublic, 2017. Disponível em:

$<$ http://www.mid.ru/en/foreign_policy/news/-

/asset_publisher/cKNonkJE02Bw/content/id/2746041>. Último acesso em: 2/11/2018.

SCIMIA, Emanuele. Turkey'scontroversial S-400 missiletransferis 'donedeal'. Asia Times, 2018. Disponível em: <http://www.atimes.com/article/turkeys-controversial-s-400transfer-is-a-done-deal/>. Último acesso em: 2/11/2018.

SELIVERSTOVA, Natalia. Venda massiva de títulos do Tesouro dos EUA: cenário apocalíptico para dólar. Sputinik News,2018. Disponível em:

<https://br.sputniknews.com/sputnik_explica/2018072611809018-titulos-tesouroeuavenda-massiva/>. Últimoacessoem: 2/11/2018.

SHAHBAZOV, Fuad. Southern Gas Corridor Project Opening New Long-Term Opportunities for Europe. The Jamestown Foundation Global Research \& Analysis,2018. Dis- 
ponívelem: <https://jamestown.org/program/southern-gas-corridor-project-openingnew-long-term-opportunities-for-europe/>. Últimoacessoem: 2/11/2018.

SIDDI, Marco. The Southern Gas Corridor: Challenges to a Geopolitical Approach in the EU's External Energy Policy. FIIA Briefing Paper 216, 2017. Helsinque: The Finnish Institute of International Affairs (FIIA).

SOCHACZEWSKI, Monique. De Atatürk a Erdoğan: A República da Turquia em três tempos. Malala, v. 6, n. 9, 2018, p. 70-90.

Syria's 'de-escalationzones' explained. Al Jazeera, 2017. Disponível em:

$<$ https://www.aljazeera.com/news/2017/05/syria-de-escalation-zones-explained170506050208636.html>. Últimoacessoem: 2/11/2018.

TALUKDAR, Indrani; ANAS, Omair. The Astana Process and the Future of Peaceful Settlement of the Syrian Crisis: A Status Note. Nova Deli: Indian Council of World Affairs, 2018. Disponívelem: <https://icwa.in/pdfs/IB/2014/TheAstanaProcess/B05032018.pdf>. Últimoacessoem: 2/11/2018.

Turkey and US lift sanctions as relations warm following Brunson's release. MiddleEastEye, 2018. Disponível em: <https://www.middleeasteye.net/news/turkeyUS-sanctions-diplomacy-1722470242>. Último acesso em: 2/11/2018.

VASCONCELLOS, Patrícia Fernandes. Da Crimeia aos Balcãs: A Projeção de Poder Rus-sa e a Questão Étnico-Cultural. Dissertação. Mestrado em Economia Política Internacional. Rio de Janeiro: Universidade Federal do Rio de Janeiro, Programa de Pós-Graduação em E-conomia Política Internacional, 2016.

WORLD NUCLEAR ASSOCIATION. Nuclear Power in Turkey, 2018. Disponível em:<http://www.world-nuclear.org/information-library/country-profiles/countries-tz/turkey.aspx>. Últimoacessoem: 2/11/2018.

YERGIN, Daniel. The Quest: Energy, Security, and the Remaking of the Modern World. Nova lorque: Penguin, 2011. 